\title{
INTEGRAL INEQUALITIES OF THE BIHARI TYPE
}

\author{
B. G. PACHPATTE
}

Abstract. In this paper a new integral inequality similar to Bihari's inequality and its two independent variable generalization are established. The discrete analogues of the main results are also given.

Mathematics subject classification (2000): 26D15.

Key words and phrases: Integral inequalities, real-valued functions.

\section{REFERENCES}

[1] D. Bainov And P. Simeonov, Integral Inequalities and Applications, Kluwer Academic Publishers, Dordrecht, 1992.

[2] R. BELLMAN, The stability of solutions of liner differential equations, Duke Math. J. 10 (1943), 643-647.

[3] I. BIHARI, A generalization of lemma of Bellman and its applications to uniqueness problems of differential equations, Acta Math. Acad. Sci. Hungar. 7 (1956), 71-94.

[4] T. E. Hull AND W. A. J. LuXEMBURG, Numerical methods and existence theorems for ordinary differential equations, Numer. Math. 2 (1960), 30-41.

[5] A. A. MARTYNIUK AND R. GUTOWSKI, Integral Inequalities and stability of motion, Naukova Dumka, Kiev (Russian), 1979.

[6] M. MEDVED, Nonlinear singular integral inequalities for functions in two and $n$ independent variables, J. Inequal. Appl. 5 (2000), 287-308.

[7] B. G. PACHPATTE, Inequalities for differential and integral equations, Academic Press, New York, 1998.

[8] B. G. PACHPATTE, On some new inequalities related to a certain inequality arising in the theory of differential equations, J. Math. Anal. Appl. 251 (2000), 736-751.

[9] B. G. PACHPATTE, Inequalities for finite difference equations, Marcel Dekker, Inc. (2001), to appear.

[10] D. Willett AND J. S. W. WONG, On the discrete analogues of some generalizations of Gronwall's inequality, Monatsh Math. 69 (1965), 362-367. 